Check for updates

Cite this: RSC Adv., 2018, 8, 15111

\title{
Transition metal triflate catalyzed conversion of alcohols, ethers and esters to olefins $\uparrow$
}

\begin{abstract}
J. Keskiväli, (D) A. Parviainen, (D) K. Lagerblom (D) and T. Repo (D)*
Herein, we report an efficient transition metal triflate catalyzed approach to convert biomass-based compounds, such as monoterpene alcohols, sugar alcohols, octyl acetate and tea tree oil, to their corresponding olefins in high yields. The reaction proceeds through $\mathrm{C}-\mathrm{O}$ bond cleavage under solventfree conditions, where the catalytic activity is determined by the oxophilicity and the Lewis acidity of the metal catalyst. In addition, we demonstrate how the oxygen containing functionality affects the formation of the olefins. Furthermore, the robustness of the used metal triflate catalysts, Fe(OTf) 3 and $\mathrm{Hf}(\mathrm{OTf})_{4}$, is highlighted by their ability to convert an over 2400 -fold excess of 2-octanol to octenes in high isolated yields.
\end{abstract}

Received 20th March 2018

Accepted 9th April 2018

DOI: $10.1039 / \mathrm{c} 8 \mathrm{ra02437e}$

rsc.li/rsc-advances

$\mathrm{C}-\mathrm{O}$ bond cleavage at elevated temperatures in the presence of $\mathrm{Pd} / \mathrm{C}$ and at high hydrogen pressures, producing alkanes as products. ${ }^{13-18}$ In this respect, the use of metal triflates in the synthesis of olefins is plausible, and ideally the more expensive metals should be replaced with more abundant and inexpensive transition metal-based Lewis acid catalysts in the conversion of biomass-based oxygen containing compounds to olefins.

Herein, we present the correlation between the oxophilicity and the Lewis-acidity of metal triflates in the dehydration of alcohols, and the aptitude of the selected transition metal triflates, $\mathrm{Fe}(\mathrm{OTf})_{3}$ and $\mathrm{Hf}(\mathrm{OTf})_{4}$, to produce olefins from various oxygen containing biomass-based compounds under solventfree conditions. The durability and robustness of $\mathrm{Fe}(\mathrm{OTf})_{3}$ and $\mathrm{Hf}(\mathrm{OTf})_{4}$ are demonstrated with a large scale synthesis of octenes from 2-octanol. As a proof of concept for the upgrading of essential oils to alkenes, tea tree oil is converted to olefins using the aforementioned metal triflate catalysts.

other purposes. ${ }^{9}$ However, more attention should be focused on finding abundant and sustainable catalysts to produce valuable olefins from renewable natural resources.

The dehydration of alcohols to alkenes is usually conducted using Brønsted acid catalysts, including $\mathrm{H}_{2} \mathrm{SO}_{4}, \mathrm{HCl}$ or $\mathrm{H}$ ZSM5. ${ }^{10-12}$ However, these catalysts are associated with various problems, such as low product selectivities, corrosive nature as well as environmental hazards., ${ }^{3,5,10}$ Accordingly, the development of more benign and selective catalysts is preferred. The use of Lewis acidic metal dehydration catalysts has been sparsely reported in the synthesis of olefins from alcohols, ethers and esters. ${ }^{10}$ On the other hand, metal triflates, such as those of Eu, Hf and La, have previously been reported to catalyze

Department of Chemistry, University of Helsinki, A. I. Virtasen aukio 1, P.O. Box 55, o0014, Finland.E-mail: timo.repo@helsinki.fi

$\uparrow$ Electronic supplementary information (ESI) available: Materials, experimental and analysis details. See DOI: 10.1039/c8ra02437e

\section{Results and discussion}

We initiated the study by investigating different catalysts in the catalytic cleavage of the alcohol $\mathrm{C}-\mathrm{O}$ bond of 2-octanol (Table 1). The catalyst scope covered different lanthanide and transition metal salts, which were mainly their triflates. Triflic acid (HOTf) was used as a reference Brønsted acid. The experiments were conducted under solvent-free reaction conditions to exclude possible solvent-effects, as, for example, coordinating solvents have been shown to reduce the dehydration activity of $\mathrm{Hf}(\mathrm{OTf})_{4}$ under hydrodeoxygenation conditions. ${ }^{\mathbf{1 3 , 1 5}}$ To rationalize the results, the octene yield and conversion were plotted as a function of the oxophilicity and Lewis acidity of the used metal cations, respectively (Fig. 1). The oxophilicity was assessed in terms of the dissociation energy of the $\mathrm{M}-\mathrm{O}$ bond, and the Lewis acidity of the metal cations was calculated using the formula: 
Table 1 Selected metal triflates, their properties and catalytic activity in the dehydration of 2-octanol ${ }^{a}$

\begin{tabular}{|c|c|c|c|c|c|}
\hline Entry & Catalyst & Oxophilicity $\left(\mathrm{kJ} \mathrm{mol}^{-1}\right)^{21}$ & Lewis acidity ${ }^{c}\left(\times 10^{-6} \mathrm{pm}^{-3}\right)$ & Conv. (\%) & Octene yield $(\%)$ \\
\hline 1 & $\mathrm{Fe}(\mathrm{OTf})_{3}$ & 409 & 11.18 & 48 & 30 \\
\hline 2 & $\operatorname{Hf}(\mathrm{OTf})_{4}$ & 791 & 11.18 & $>99$ & 93 \\
\hline 4 & $\mathrm{Sc}(\mathrm{OTf})_{3}$ & 674 & 7.26 & 20 & 6 \\
\hline 5 & $\mathrm{Yb}(\mathrm{OTf})_{3}$ & 398 & 4.59 & 8 & 1 \\
\hline 6 & $\mathrm{Y}(\mathrm{OTf})_{3}$ & 715 & 4.11 & 5 & 1 \\
\hline 9 & $\mathrm{Al}(\mathrm{OTf})_{3}$ & 512 & 19.59 & 75 & 34 \\
\hline 10 & $\operatorname{Mg}(\mathrm{OTf})_{2}$ & 394 & 5.36 & 10 & 4 \\
\hline 11 & $\operatorname{Pr}(\mathrm{OTf})_{3}$ & 753 & 3.09 & 10 & 1 \\
\hline 12 & $\mathrm{Ti}(\mathrm{OTf})_{4}$ & 662 & 18.06 & $>99$ & 71 \\
\hline 13 & $\mathrm{Cr}(\mathrm{OTf})_{3}$ & 427 & 12.90 & 73 & 35 \\
\hline 14 & $\mathrm{FeCl}_{3}$ & 409 & 11.18 & 11 & 0 \\
\hline
\end{tabular}

${ }^{a}$ Reaction conditions: $3 \mathrm{~h}, 150{ }^{\circ} \mathrm{C}, 0.5 \mathrm{~mol} \%$ of catalyst using a closed batch type reaction vessel. ${ }^{b}$ Mixture of 1-octene and cis/trans isomers of 2-, 3and 4-octene, yields obtained with GC-FID using calibration curves. ${ }^{c}$ Lewis acidity $=Z / r^{3}$, unit $1 / \mathrm{pm}^{3}$. The effect of anions has not been taken into account in the calculated Lewis acidity.

Lewis acidity $=Z / r^{3}(Z=$ charge of the metal and $r=$ ionic radius of the cation in pm). ${ }^{19-21}$

Interestingly, the plots revealed a clear dependence of the reaction outcome on the oxophilicity and Lewis acidity of the metal cations (Table 1 \& Fig. 1). In general, the metals with relatively high Lewis acidity $\left(>10 \times 10^{-6}\right)$ gave significantly better conversions than those catalysts with lower Lewis acidity $\left(<10 \times 10^{-6}\right.$, Fig. 1A). Further comparison of the octene yields as a function of oxophilicity with the five most Lewis acidic metal cations $\left(\mathrm{Fe}(\mathrm{OTf})_{3}, \mathrm{Cr}(\mathrm{OTf})_{3}, \mathrm{Al}(\mathrm{OTf})_{3}, \mathrm{Ti}(\mathrm{OTf})_{4}\right.$ and $\left.\mathrm{Hf}(\mathrm{OTf})_{4}\right)$ revealed a linear correlation (Fig. 1B). While $\mathrm{Fe}(\mathrm{OTf})_{3}, \mathrm{Cr}(\mathrm{OTf})_{3}$ and $\mathrm{Al}(\mathrm{OTf})_{3}$ gave octenes in moderate yields of $30-40 \%$, the most oxophilic $\mathrm{Hf}(\mathrm{OTf})_{4}$ and $\mathrm{Ti}(\mathrm{OTf})_{4}$ generated quantitative conversion of 2-octanol, and octenes were formed in high 93\% and $71 \%$ yields, respectively. The reference Brønsted acid catalyst, HOTf, generated quantitative conversion of 2-octanol with $84 \%$ yield of octenes (Table 1 , entry 18 ). In addition to olefin products, unidentified by-products were formed in all of the experiments.

Additional experiments were conducted with $\mathrm{Fe}(\mathrm{OTf})_{3}$, $\mathrm{Cr}(\mathrm{OTf})_{3}$ and $\mathrm{Al}(\mathrm{OTf})_{3}$ at an elevated temperature of $165{ }^{\circ} \mathrm{C}$ using 2-octanol as a substrate. This resulted in quantitative conversions and enhanced yields of $80-85 \%$, matching those of HOTf, $\operatorname{Hf}(\mathrm{OTf})_{4}$ and Ti(OTf $)_{4}$ at $150{ }^{\circ} \mathrm{C}$ (see Table S1 in ESI $\dagger$ ). The replacement of the triflate anion with chloride resulted in a significantly reduced yield and conversion (Table 1, entries 14-17). The better reactivity with triflates can be explained by the weak electron donor and strong electron acceptor nature of this anion, which increases the Lewis acidity of the central metal atom. ${ }^{22}$ In contrast, chloride, acetate, nitrate and sulphate are $\pi$-donating middle and low field ligands, according to the spectrochemical series, and because of this they are unlikely to impart greater Lewis acidity. ${ }^{23}$ Additionally, some of the metal chlorides form $\mathrm{HCl}$ when they come into contact with water (e.g. $\mathrm{AlCl}_{3}, \mathrm{HfCl}_{4}$ and $\mathrm{TiCl}_{4}$ ), thus possessing similar unwanted properties to Brønsted acids, such as HOTf.

Next, we measured the conversion rates of 2-octanol (6.3 mmol) with $0.5 \mathrm{~mol} \%$ loadings of $\mathrm{Fe}(\mathrm{OTf})_{3}, \mathrm{Cr}(\mathrm{OTf})_{3}, \mathrm{Al}(\mathrm{OTf})_{3}$, $\mathrm{Ti}(\mathrm{OTf})_{4}$ and $\mathrm{Hf}(\mathrm{OTf})_{4}$ at $150{ }^{\circ} \mathrm{C}$. The reactions were monitored using GC-FID with sampling intervals of $5 \mathrm{~min}, 15 \mathrm{~min}, 30 \mathrm{~min}$, $1 \mathrm{~h}, 1.5 \mathrm{~h}, 2 \mathrm{~h}$ and $3 \mathrm{~h}$. The conversion had a linear correlation with time, indicating that the reaction follows zero-order kinetics (Fig. 2). This is common in catalytic reactions where a catalyst is in large excess of substrates. The order of the reaction arises through saturated catalyst activity, forcing the catalyst to work at the maximum capacity until the substrate is nearly consumed. The observed rates of the reactions with different metal triflates were in a similar order as the initial catalyst screening. $\mathrm{Hf}(\mathrm{OTf})_{4}$ generated the highest conversion rate of $2.76 \mathrm{mmol} \mathrm{h}^{-1}$, which was three times higher than that with $\mathrm{Fe}(\mathrm{OTf})_{3}$. Overall, the order of the conversion rates is $\mathrm{Hf}(\mathrm{OTf})_{4}>\mathrm{Ti}(\mathrm{OTf})_{4}>\mathrm{Al}(\mathrm{OTf})_{3}>\mathrm{Cr}(\mathrm{OTf})_{3}>\mathrm{Fe}(\mathrm{OTf})_{3}$. For further studies we selected $\mathrm{Fe}(\mathrm{OTf})_{3}$, due to its benign and non-toxic nature, and the most efficient $\mathrm{Hf}(\mathrm{OTF})_{4}$ as catalyst. The catalytic activity and efficiency of $\mathrm{Ti}(\mathrm{OTf})_{4}, \mathrm{Al}(\mathrm{OTf})_{3}$ and $\mathrm{Cr}(\mathrm{OTf})_{3}$ in the following experiments could be expected to be in between that of $\mathrm{Hf}(\mathrm{OTf})_{4}$ and $\mathrm{Fe}(\mathrm{OTf})_{3}$.

The effect of the position of the hydroxyl group on the $\mathrm{Hf}(\mathrm{OTf})_{4}$ and $\mathrm{Fe}(\mathrm{OTf})_{3}$ catalyzed dehydration reactions was studied using primary, secondary and tertiary alcohols (Table 2 ). The reactions were conducted in a solvent-free manner in a flask connected to micro distillation apparatus, allowing the distillation and isolation of the alkenes upon formation. To ensure efficient conversion, the reactions catalyzed by $\mathrm{Fe}(\mathrm{OTf})_{3}$ were conducted at higher temperatures than those with $\mathrm{Hf}(\mathrm{OTf})_{4}$. The tertiary alcohol, 3-ethylpentan-3-ol as a substrate, 

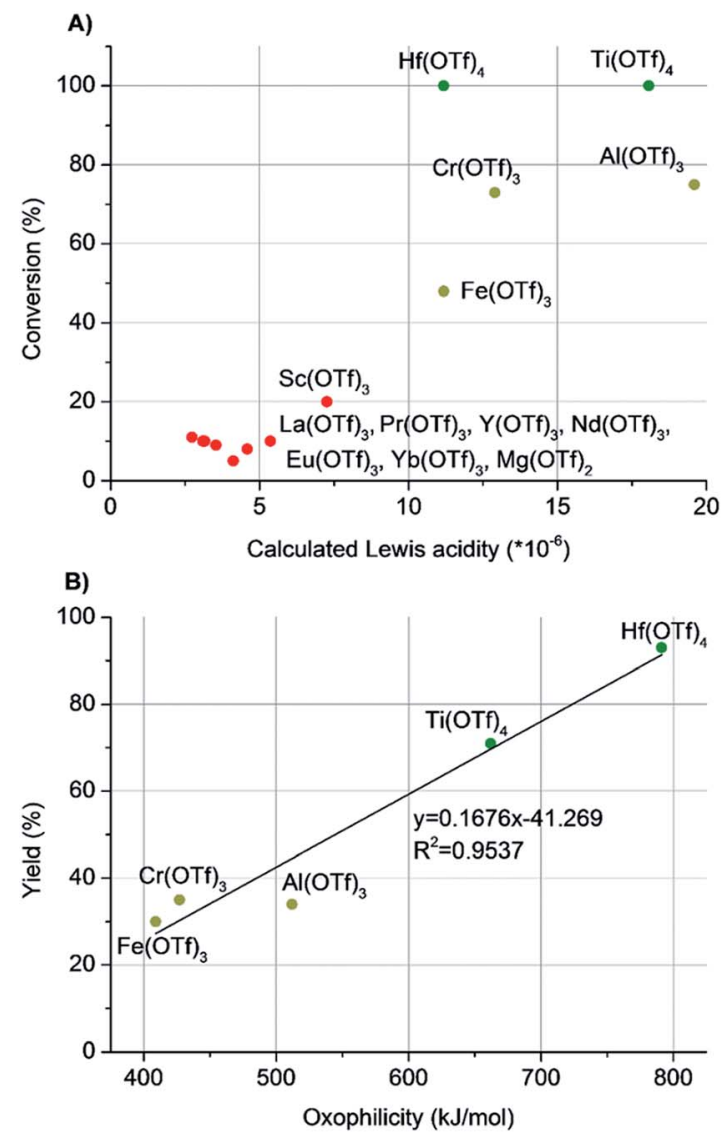

Fig. 1 (A) The conversion of 2-octanol as a function of the Lewis acidity of the metal triflate. The Lewis acidity is calculated for the metal cations, and the effect of the triflate anion is not included. (B) The yield of octenes as a function of the oxophilicity of the metal cation in the dehydration of 2-octanol. The oxophilicity is the measured $\mathrm{M}-\mathrm{O}$ bond dissociation energy. ${ }^{21}$

was converted to 3-ethylpent-3-ene in isolated yields of $79 \%$ and $84 \%$ using $\mathrm{Fe}(\mathrm{OTf})_{3}$ and $\mathrm{Hf}(\mathrm{OTf})_{4}$, respectively (Table 2, entry 3 ). With the secondary, alcohols 2-octanol and cyclohexanol, higher reaction temperatures were required than with the tertiary alcohol. With $\mathrm{Fe}(\mathrm{OTf})_{3}$, octenes from 2-octanol were obtained in a slightly higher $91 \%$ yield than the $85 \%$ yield with $\mathrm{Hf}(\mathrm{OTf})_{4}$ (Table 2, entry 1). Various isomers of octene were observed, and the product ratio of 2-, 3- and 4-octene to 1-octene was $10: 1$ with both the catalysts (see Fig. S5 in ESI†). Cyclohexanol was converted to cyclohexene in $80 \%$ and $78 \%$ yield with $\mathrm{Hf}(\mathrm{OTf})_{4}$ and $\mathrm{Fe}(\mathrm{OTf})_{3}$, respectively (Table 2, entry 4). Full conversion of the primary alcohol, 1-octanol, was achieved after $6 \mathrm{~h}$ at $180{ }^{\circ} \mathrm{C}$ using $\mathrm{Fe}(\mathrm{OTf})_{3}$ as a catalyst (Table 2, entry 2). Unexpectedly, dioctyl ether was the main product with $80 \%$ yield, which was accompanied by octene in only $2 \%$ yield, and the rest being unidentified side products. Due to this, no further $\mathrm{Fe}(\mathrm{OTf})_{3}$ catalyzed experiments with primary alcohols were conducted. With $\mathrm{Hf}(\mathrm{OTf})_{4}$, 1-octanol was converted to octenes, generating $46 \%$ yield in 6 hours and 65\% yield in 12 hours at $180{ }^{\circ} \mathrm{C}$ (Table 2 , entry 2 ). The ratio of 2-, 3- and 4-octene to 1 octene was $30: 1$. The reactivity of the alcohols was found to

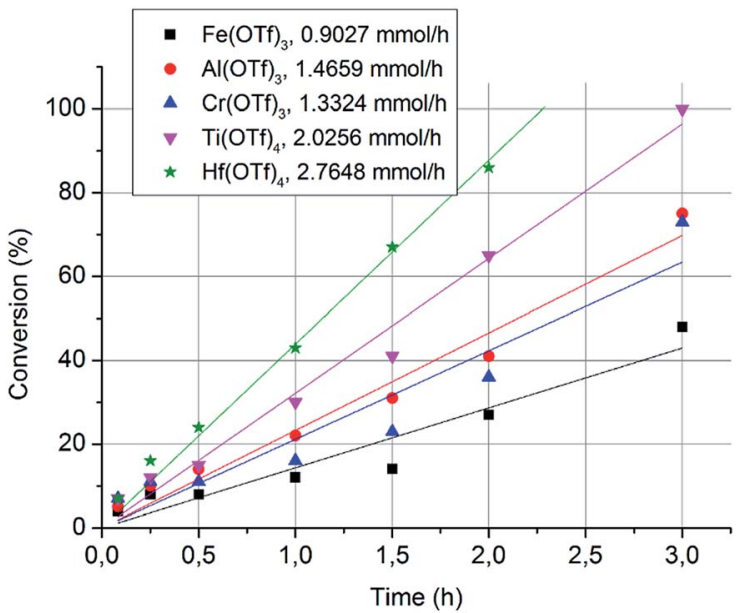

Fig. 2 The conversion of 2-octanol with respect to time-on-stream. The conversion rates were calculated based on the slopes of the fitted curves.

decrease in the order of tert- $>$ sec- $>$ prim-alcohols, which is analogous to the order of the stability of the carbocations, and is in line with previous publications. ${ }^{10}$ Furthermore, the dehydration of diethylene glycol produced a good $84 \%$ yield of 1,4dioxane with $\mathrm{Hf}(\mathrm{OTf})_{4}$ (Table 2, entry 7). The dehydration of 1phenylpropan-1-ol and 3-phenylpropan-1-ol resulted in formation of non-volatile compounds, and little of the desired dehydrated products were obtained (Table 2 , entries $5 \& 6$ ).

The efficiency and robustness of $\mathrm{Fe}(\mathrm{OTf})_{3}$ and $\mathrm{Hf}(\mathrm{OTf})_{4}$ in the dehydration reaction was studied by conducting experiments using $0.06 \mathrm{mmol}$ of the metal triflates and $144.9 \mathrm{mmol}$ of 2 octanol, which is equal to $0.04 \mathrm{~mol} \%$ catalyst loading. During the reaction, 2-octanol was added dropwise using a dropping funnel to keep the amount of substrate constant, while the octenes formed were distilled. The catalysts converted an over 2400 -fold excess of 2-octanol during the reaction, and with the use of $\mathrm{Hf}(\mathrm{OTf})_{4}$ octenes were generated in $84 \%$ isolated yield in 10 hours, while $\mathrm{Fe}(\mathrm{OTf})_{3}$ produced octenes in $80 \%$ yield in 24 hours at $165{ }^{\circ} \mathrm{C}$. These experiments underscore the robust performance of the metal triflate catalysts in the dehydration.

We moved on to study the formation of the isomers during the dehydration reactions. Based on the literature, two possible pathways were recognized: (i) migration of the charge in the carbocation intermediate and (ii) alkene hydration (Scheme 1). ${ }^{24,25}$ The isomerization mechanisms were studied by heating 1-octene in the presence of $\mathrm{Hf}(\mathrm{OTf})_{4}$ with and without water at $150{ }^{\circ} \mathrm{C}$. In the absence of water, 1-octene seemingly underwent oligomerization, forming a viscous dark brown oil. The measured ${ }^{1} \mathrm{H}$ NMR spectrum shows that the signals corresponding to the alkene protons were suppressed and shifted, and also that the saturated carbon chain $\mathrm{C}-\mathrm{H}$ signals were clearly broadened (see Fig. S23 in ESI $\dagger$ ). This oligomerization might explain the formation of the non-volatile compounds from the aromatic alcohols. ${ }^{26}$ Based on the ${ }^{1} \mathrm{H}$ NMR analysis, octene isomers or oligomers do not form in the presence of water, which indicates that the isomers are formed through the 
Table 2 The results of dehydration of different alcohols with 0.5 mol\% loading of Fe(OTf $)_{3}$ or $\mathrm{Hf}(\mathrm{OTf})_{4}{ }^{a}$

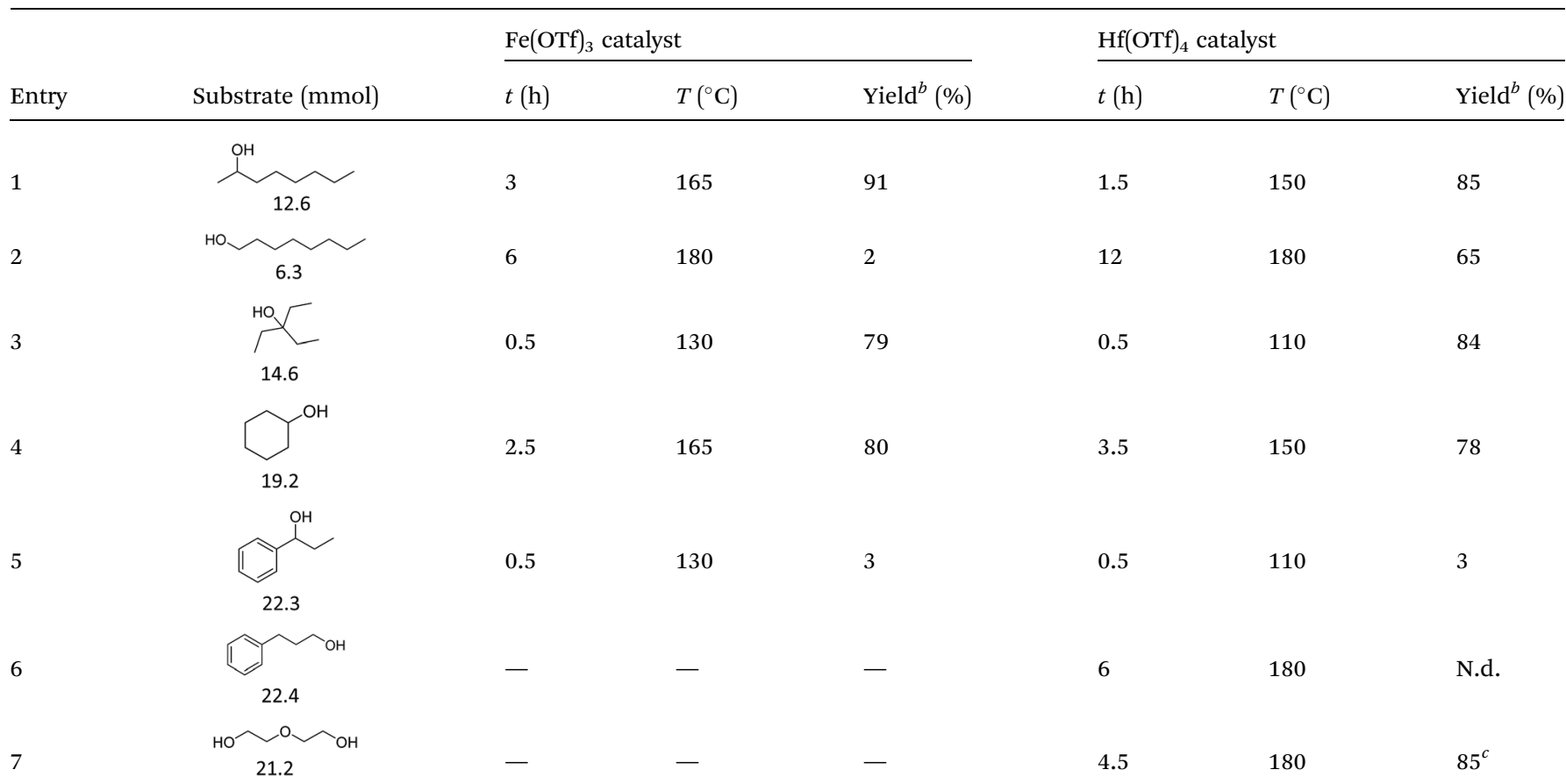

${ }^{a}$ N.d. = not detected. ${ }^{b}$ Isolated olefin yields obtained by distillation of the products during the reaction. Analyzed using GC-MS, ${ }^{1} \mathrm{H}$ NMR and ${ }^{13} \mathrm{C}$ NMR (see ESI). ${ }^{c}$ 1,4-Dioxane was the reaction product.

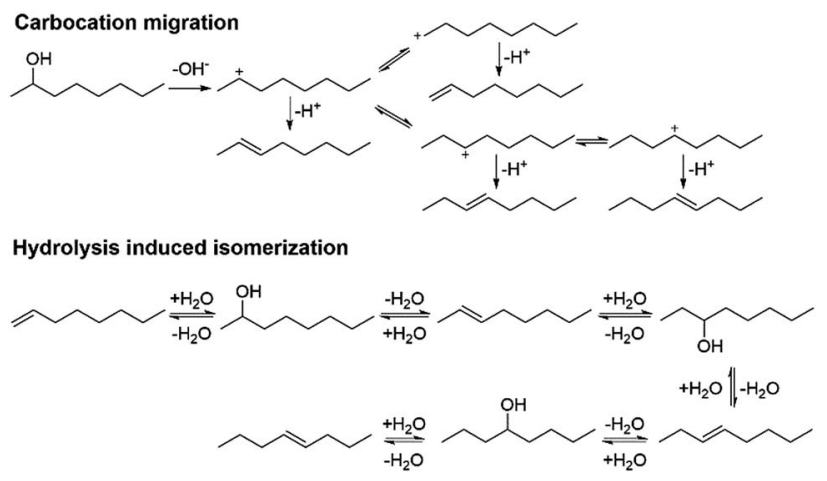

Scheme 1 Two putative pathways for octene isomerization: carbocation migration and hydrolysis induced isomerization.

migration of the carbocation in the transition state. This proposition is in agreement with the previous report on the isomerization of alkenes. ${ }^{24}$ The addition of water decreases the oligomerization through the formation of a biphasic system and the solvation of $\mathrm{Hf}(\mathrm{OTf})_{4}$, thus limiting the interaction of the catalyst and the alkenes.

Due to the promising results obtained using the model alcohols, we conducted $\mathrm{Fe}(\mathrm{OTf})_{3}$ and $\mathrm{Hf}(\mathrm{OTf})_{4}$ catalyzed dehydration of the biomass-based monoterpene alcohols. The reactions were conducted in a solvent-free manner using micro distillation apparatus to isolate the products as they formed (Table 3). Some reactions were conducted under reduced pressure to ensure the distillation of the products. The main emphasis was on the secondary and tertiary monoterpene alcohols, due to their more reactive nature. Using menthol and dihydromyrcenol, $71-84 \%$ isolated yields of the corresponding terpenes and dihydromyrcenes were obtained with both metal triflates (Table 3 , entries 1 \& 2). With $\mathrm{Fe}(\mathrm{OTf})_{3}$, $\alpha$-terpineol was successfully converted to limonene, $\alpha$-terpinen, $\gamma$-terpinen and $\alpha$-terpinolene in $76 \%$ yield. Meanwhile, $\mathrm{Hf}(\mathrm{OTf})_{4}$ gave only $16 \%$ yield of the olefins and mainly formed a viscous non-volatile oily substance similar to with the aromatic alcohols (Table 3, entry 3). The formation of non-volatile oils was also observed with linalool and citronellol (Table 3, entries 4 \& 5). In fact, all of the secondary and tertiary alcohols forming these non-volatile oils had electron donating groups, such as methyl, connected to the $\mathrm{sp}^{2}$-hybridized carbon. This is known to facilitate cationic polymerization. ${ }^{9}$ It is also known that metal halides are capable of catalyzing cationic polymerization, and thus it is likely that the non-volatile oils herein are a result of metal triflate catalyzed cationic oligomerization..$^{27,28}$ It is therefore rational that the more Lewis acidic and oxophilic, and thus stronger dehydration catalyst, $\mathrm{Hf}(\mathrm{OTf})_{4}$ also catalyzes the oligomerization more efficiently than $\mathrm{Fe}(\mathrm{OTf})_{3}$ (Table 3, entry 3). The dehydration of sugar alcohols was studied using sorbitol, which is readily available from cellulose- and hemicellulose-based glucose. ${ }^{29}$ As a result, isosorbide was generated in yields of $77 \%$ and $78 \%$ with $\mathrm{Fe}(\mathrm{OTf})_{3}$ and $\mathrm{Hf}(\mathrm{OTf})_{4}$ as the catalysts, respectively (Table 3 , entry 6). In comparison to the previously published metal triflate-catalyzed conversion of sorbitol to isosorbide, the use of $\mathrm{Fe}(\mathrm{OTf})_{3}$ and $\mathrm{Hf}(\mathrm{OTf})_{4}$ afforded isosorbide in similar yields but in shorter reaction times and with lower catalyst loadings. ${ }^{30,31}$ 
Table 3 The results of the solvent-free dehydration of alcohols with 0.5 mol\% loading of Fe(OTf) 3 or $\mathrm{Hf}(\mathrm{OTf})_{4}$

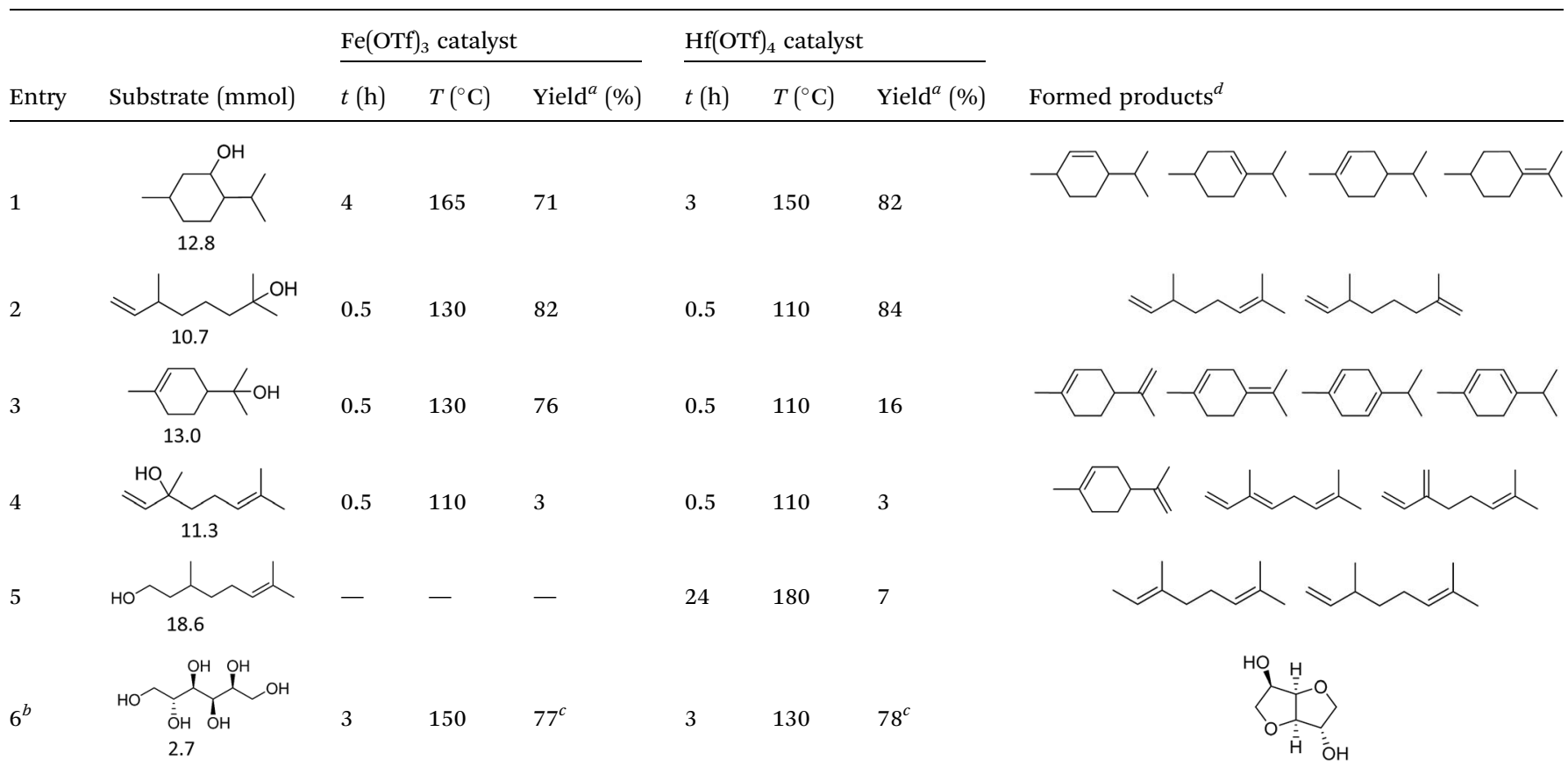

\footnotetext{
${ }^{a}$ Isolated yields obtained by distillation of the olefins during the reaction. Analyzed using GC-MS, ${ }^{1} \mathrm{H}$ NMR and ${ }^{13} \mathrm{C}$ NMR (see ESI). ${ }^{b}$ Batch type reaction was conducted in vacuo to increase the efficiency of the dehydration, and product yields were measured using HPLC-FID and calibration curves, with isosorbide as the reaction product. ${ }^{c}$ Product yields were determined using HPLC-FID and calibration curves, with isosorbide as the reaction product. ${ }^{d}$ Product distributions are presented in the ESI.
}

As metal triflates could potentially catalyze the conversion of essential oils to olefins, we composed an experiment as a proof of concept using tea tree oil as a substrate in $\mathrm{Fe}(\mathrm{OTf})_{3}$ and $\mathrm{Hf}(\mathrm{OTf})_{4}$ catalyzed dehydration reactions. Tea tree oil consists mainly of terpinen-4-ol, thus providing an ample source of biomass-based alcohol for the synthesis of olefins. ${ }^{32,33}$ With the use of $\mathrm{Fe}(\mathrm{OTf})_{3}$, a mixture of products, mainly $\alpha$ - and $\gamma$-terpinenes, was generated in $53 \mathrm{wt} \%$ yield from tea tree oil in 1 hour under a reduced pressure of $57 \mathrm{mmHg}$ at $130{ }^{\circ} \mathrm{C}$. However, the $\mathrm{Hf}(\mathrm{OTf})_{4}$-catalyzed reaction produced non-volatile products at $110{ }^{\circ} \mathrm{C}$ under reduced pressure, and as a result no olefins were obtained. The reaction results resemble those of the $\alpha$-terpineol dehydration, where $\mathrm{Fe}(\mathrm{OTf})_{3}$ gave a good olefin yield while $\mathrm{Hf}(\mathrm{OTf})_{4}$ generated mostly non-volatile products (Table 3 , entry 3$)$.

We also investigated two metal triflate-catalyzed nonhydrogenolytic approaches to the scission of ester and ether C-O bonds: (i) direct cleavage and (ii) hydrolysis, followed by the dehydration of the hydroxyl groups to alkenes (Scheme 2). Previously, ester and ether $\mathrm{C}-\mathrm{O}$ bond cleavage has been achieved through hydrogenolysis catalyzed by $\mathrm{Hf}(\mathrm{OTf})_{4}$ and $\mathrm{Pd} /$ C. ${ }^{18,34}$ Accordingly, on dioctyl ether and octyl acetate we carried out several reactions with and without water to see the effect of hydrolysis (Table 4). It turned out that the use of $\mathrm{Hf}(\mathrm{OTf})_{4}$ and water (1-2 mol eq.) resulted in the hydrolysis of dioctylether, forming 1-octanol. Subsequently, the as-formed 1-octanol was dehydrated to octenes, although in relatively low yields. The highest yield of $29 \%$ was obtained after 24 hours at $180{ }^{\circ} \mathrm{C}$ (Table 4 , entries $8 \& 9$ ). No alkenes were detected using $\mathrm{Hf}(\mathrm{OTf})_{4}$ without additional water (Table 4, entry 10). Evidently, water is an essential additive to convert the ethers to alcohols through hydrolysis, followed by the yield-reducing cumbersome dehydration of the primary alcohols to alkenes. However, $\mathrm{Fe}(\mathrm{OTf})_{3}$ could not convert dioctyl ether to alkenes or alcohols in significant amounts with either approach (see Table S2 in ESI†). The attempted conversion of dimethyl tetrahydrofuran to olefins through hydrolysis and subsequent dehydration failed to produce any olefin products with either of the used catalysts, $\mathrm{Fe}(\mathrm{OTf})_{3}$ or $\operatorname{Hf}(\mathrm{OTf})_{4}$.

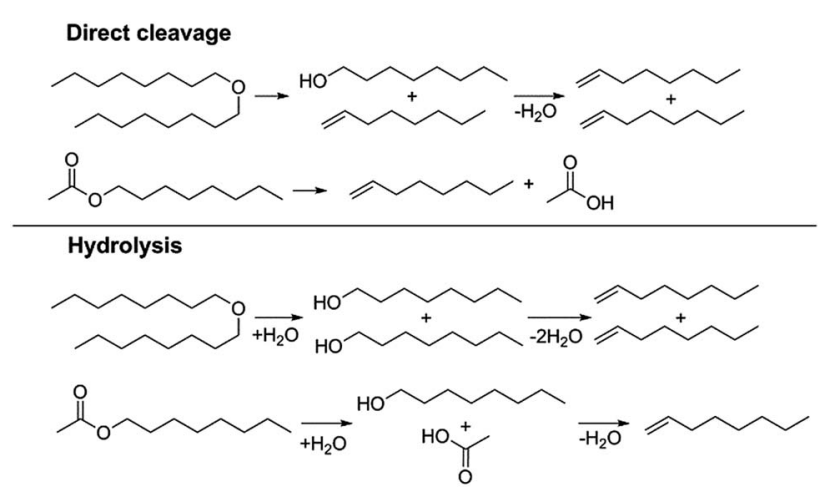

Scheme 2 Two theoretical pathways for alkene formation from dioctyl ether and octyl acetate. 
Table 4 The results of the conversion of dioctyl ether and octyl acetate into octenes with 0.5 mol\% loading of Fe(OTf $)_{3}$ or $\mathrm{Hf}(\mathrm{OTf})_{4}{ }^{a}$

\begin{tabular}{|c|c|c|c|c|c|}
\hline Entry & Catalyst & Substrate (mmol) & Time (h) & Temp. $\left({ }^{\circ} \mathrm{C}\right)$ & Octene yield ${ }^{b}(\%)$ \\
\hline 1 & $\mathrm{Fe}(\mathrm{OTf})_{3}$ & 5.0 & 3 & 170 & 4 \\
\hline 2 & $\mathrm{Fe}(\mathrm{OTf})_{3}{ }^{d}$ & 5.0 & 3 & 170 & 4 \\
\hline 4 & $\operatorname{Hf}(\mathrm{OTf})_{4}$ & 5.0 & 3 & 150 & 13 \\
\hline 5 & $\mathrm{Hf}(\mathrm{OTf})_{4}{ }^{d}$ & 5.0 & 3 & 170 & 5 \\
\hline 7 & $\mathrm{Hf}(\mathrm{OTf})_{4}$ & 10.1 & 22 & 180 & $80^{c}$ \\
\hline 8 & $\mathrm{Hf}(\mathrm{OTf})_{4}{ }^{d}$ & 3.3 & 8 & 180 & 7 \\
\hline 9 & $\mathrm{Hf}(\mathrm{OTf})_{4}{ }^{d}$ & 3.3 & 24 & 180 & 29 \\
\hline 10 & $\mathrm{Hf}(\mathrm{OTf})_{4}$ & 3.3 & 8 & 180 & N.d. \\
\hline
\end{tabular}

${ }^{a}$ N.d. $=$ not detected. ${ }^{b}$ Yield determined using GC-FID and calibration curves. ${ }^{c}$ Isolated yields obtained by distillation of the olefins during the reaction. Analyzed using GC-MS, ${ }^{1} \mathrm{H}$ NMR and ${ }^{13} \mathrm{C}$ NMR. ${ }^{d} 1$ equivalent of $\mathrm{H}_{2} \mathrm{O}$ added to induce hydrolysis of the ether/ester bond.

The hydrolysis experiments with octyl acetate generated octenes with both approaches and catalysts (Table 4, entries 2 \& 5). In general, the addition of water resulted in the formation of 1-octanol and acetic acid as the hydrolysis products. However, this approach leads to low alkene yields, as dehydration of the primary hydroxyl group is difficult even with $\mathrm{Hf}(\mathrm{OTf})_{4}$ (see above). In this respect, the addition of water should be avoided. Without water, the direct ester $\mathrm{C}-\mathrm{O}$ cleavage approach resulted in the formation of acetic acid and octene from octyl acetate through the scission of the alkoxy $\mathrm{C}-\mathrm{O}$ bond (Table 4, entries 1 , 4 \& 6). This direct approach generated high isolated yields of $68 \%$ and $80 \%$ of octenes with $\mathrm{Fe}(\mathrm{OTf})_{3}$ and $\mathrm{Hf}(\mathrm{OTf})_{4}$, respectively (Table 4 , entries $3 \& 7$ ). Compared to the previous Lewis acid catalyzed synthesis of olefins, our setup allows the use of benign and abundant transition metal triflate catalysts as well as various alcohols, esters and ethers as substrates. ${ }^{\mathbf{1 0 , 3 5}}$ Furthermore, the solvent-free approach enables the isolation of the products in good yields as they form.

The compatibility of aldehydes and carboxylic acids as substrates was also investigated. Under the applied conditions, aldehydes underwent an immediate oligomerization to nonvolatile oils, while carboxylic acids did not undergo any conversion using $\mathrm{Fe}(\mathrm{OTf})_{3}$ and $\mathrm{Hf}(\mathrm{OTf})_{4}$, although the deoxygenation of carboxylic acids has been reported to occur under similar conditions with Pd or Pt as catalysts. ${ }^{36}$

\section{Conclusions}

In summary, highly oxophilic and Lewis acidic metal triflates can be used to catalyze the cleavage of $\mathrm{C}-\mathrm{O}$ bonds of biomassbased alcohols, esters and ethers to give the corresponding olefins. The catalytic activity of the transition metal triflates improved with increasing oxophilicity and Lewis-acidity. Understanding of this correlation aids in the development of new transition metal based defunctionalization catalysts. The reactivity order of the different oxygen containing species to alkenes is tert-alcohols $>$ sec-alcohols $>$ esters $>$ prim-alcohols $>$ ethers. Alcohols and esters can be converted efficiently to olefins under solvent-free conditions using metal triflate catalysts. However, the conversion of ethers to alkenes requires initial hydrolysis of the ether bond to an alcohol, which is then followed by the dehydration of the formed alcohol. The proof of concept experiments demonstrated that the studied Fe(OTf $)_{3}$ and $\mathrm{Hf}(\mathrm{OTf})_{4}$ are very robust catalysts, as in the solvent-free 
continuous distillation process they converted an over 2400 -fold excess of 2-octanol into octenes in high yields of $84 \%$ and $80 \%$, respectively. Also, the usability of essential oils as substrates was established by the dehydration of tea tree oil, producing alkenes in up to $53 \mathrm{wt} \%$ yield.

\section{Experimental}

\section{General procedure for the synthesis of olefins}

The desired amount of catalyst $(0.5 \mathrm{~mol} \%$, unless otherwise stated) was placed into a reaction vessel, to which an appropriate amount of substrate and any additives, such as water, were added. The vessel was heated with an oil bath at a suitable temperature. Batch type reactions were conducted in a closed vial, and the distillation reactions were conducted using micro distillation apparatus at atmospheric or reduced pressure, depending on the substrate. The forming products and side products, water or acetic acid, were distilled and collected in a product flask, which was cooled with an ice bath to minimize evaporation of the products. The distillation reactions were continued until completion, and no more products could be recovered. After the reaction, when water was the side product the product flask was placed in a freezer for ease of separation of the olefin products from the frozen water. In the case of acetic acid as the side product, the acetic acid-olefin mixture was washed with $1 \mathrm{M} \mathrm{NaOH}(\mathrm{aq})$ to neutralize the acetic acid. Pure olefin products were obtained after drying with $\mathrm{Na}_{2} \mathrm{SO}_{4}$ and filtration. The reaction products were then analysed using GCFID, GC-MS, ${ }^{1} \mathrm{H}$ NMR and ${ }^{13} \mathrm{C}$ NMR. For a detailed description of the experimental setups see the ESI. $\dagger$

\section{GC-analysis}

The reaction products were analysed using an Agilent Technologies 7890B GC System equipped with a flame ionization detector (FID) and an Agilent Technologies 5977C MSD mass detector (MS). HP-5MS UI (30 m, $0.25 \mathrm{~mm}, 0.25 \mu \mathrm{m})$ was used as the column in the GC-analysis.

\section{NMR-analysis}

Nuclear magnetic resonance (NMR) experiments $\left({ }^{1} \mathrm{H}\right.$ and $\left.{ }^{13} \mathrm{C}\right)$ were conducted using a Varian Mercury Plus $300 \mathrm{MHz}\left({ }^{1} \mathrm{H}\right.$ frequency $300 \mathrm{MHz}$ and ${ }^{13} \mathrm{C}$ frequency $75 \mathrm{MHz}$ ) and deuterated solvents.

\section{HPLC-analysis}

High-performance liquid chromatography (HPLC) analysis was conducted using an Agilent Technologies 1200 Series HPLC equipped with Phenomenex Rezex ROA - organic acid $\mathrm{H}^{+}(8 \%)$ $(300 \times 7.80 \mathrm{~mm})$ column and refractive index detector (RID). A $5 \mathrm{mM} \mathrm{H}_{2} \mathrm{SO}_{4}$ aqueous solution was used as the eluent with the

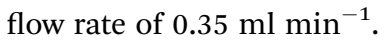

\section{Conflicts of interest}

There are no conflicts to declare.

\section{Notes and references}

1 S. V. Vassilev, D. Baxter, L. K. Andersen, C. G. Vassileva and T. J. Morgan, Fuel, 2012, 94, 1-33.

2 G. W. Huber, J. Chheda, C. B. Barrett and J. A. Dumesic, Science, 2005, 308, 1446-1450.

3 S. Van de Vyver, J. Geboers, P. A. Jacobs and B. F. Sels, ChemCatChem, 2011, 3, 82-94.

4 A. A. Rosatella, S. P. Simeonov, R. F. M. Frade and C. A. M. Afonso, Green Chem., 2011, 13, 754-793.

5 R. Karinen, K. Vilonen and M. Niemelä, ChemSusChem, 2011, 4, 1002-1016.

6 M. Rose and R. Palkovits, ChemSusChem, 2012, 5, 167-176.

7 A. Corma Canos, S. Iborra and A. Velty, Chem. Rev., 2007, 107, 2411-2502.

8 O. Lasekan and K. A. Abbas, Crit. Rev. Food Sci. Nutr., 2012, 52, 726-735.

9 P. A. Wilbon, F. Chu and C. Tang, Macromol. Rapid Commun., 2013, 34, 8-37.

10 T. J. Korstanje, E. F. de Waard, J. T. B. H. Jastrzebski and R. J. M. Klein Gebbink, ACS Catal., 2012, 2, 2173-2181.

11 M. Eisenacher, S. Beschnitt and W. Hölderich, Catal. Commun., 2012, 26, 214-217.

12 M.-H. Lee, S.-W. Lee, Y.-M. Jeong, D.-Y. Park and J.-Y. Ryu, WO 2005035468, 2005.

13 Z. Li, R. S. Assary, A. C. Atesin, L. A. Curtiss and T. J. Marks, J. Am. Chem. Soc., 2014, 136, 104-107.

14 J. Keskiväli, P. Wrigstedt, K. Lagerblom and T. Repo, Appl. Catal., A, 2017, 534, 40-45.

15 H. J. Song, J. Deng, M. S. Cui, X. L. Li, X. X. Liu, R. Zhu, W. P. Wu and Y. Fu, ChemSusChem, 2015, 8, 4250-4255.

16 A. D. Sutton, F. D. Waldie, R. Wu, M. Schlaf, A. Louis III and J. C. Gordon, Nat. Chem., 2013, 5, 428-432.

17 A. E. King, T. J. Brooks, Y.-H. Tian, E. R. Batista and A. D. Sutton, ACS Catal., 2015, 5, 1223-1226.

18 T. L. Lohr, Z. Li and T. J. Marks, ACS Catal., 2015, 5, 70047007.

19 K. Mikami, M. Terada and H. Matsuzawa, Angew. Chem., Int. Ed., 2002, 41, 3554-3572.

20 R. D. Shannon, Acta Crystallogr., Sect. A: Cryst. Phys., Diffr., Theor. Gen. Crystallogr., 1976, 32, 751-767.

21 J. A. Dean, Lange's Handbook of chemistry, McGraw-Hill, Inc, New York, 1985.

22 S. Voigt, H. Glaum, S. Schlecht, J. Magull, D. Fenske and K. Dehnicke, Communications, 1997, 3, 1994-1995.

23 Y. Shimura, Bull. Chem. Soc. Jpn., 1988, 61, 693-698.

24 V. Macho, M. Králik, E. Jurecekova, J. Hudec and L. Jurecek, Appl. Catal., A, 2001, 214, 251-257.

25 M. B. Smith and J. March, March's advanced organic chemistry, John Wiley \& Sons, Inc., New Jersey, 6th edn, 2007.

26 C. H. Bartholomew, Appl. Catal., A, 2001, 212, 17-60.

27 W. J. Roberts and A. R. Day, J. Am. Chem. Soc., 1950, 72, 12261230.

28 J. Lu, M. Kamigaito, M. Sawamoto, T. Higashimura and Y.-X. Deng, J. Appl. Polym. Sci., 1996, 61, 1011-1016. 
29 W. Deng, X. Tan, W. Fang, Q. Zhang and Y. Wang, Catal. Lett., 2009, 133, 167-174.

30 F. Liu, K. De Oliveira Vigier, M. Pera-Titus, Y. Pouilloux, J.-M. Clacens, F. Decampo and F. Jérôme, Green Chem., 2013, 15, 901-909.

31 K. Stensrud, E. Hagberg, S. Howard and E. M. Rockafellow, WO 2014137619 A1, 2014.

32 J. J. Brophy, N. W. Davies, I. A. Southwell, I. A. Stiff and L. R. Williams, J. Agric. Food Chem., 1989, 37, 1330-1335.
33 G. Swords and G. L. K. Hunter, J. Agric. Food Chem., 1978, 26(3), 734-737.

34 T. L. Lohr, Z. Li, R. S. Assary, L. A. Curtiss and T. J. Marks, Energy Environ. Sci., 2016, 9, 550-564.

35 Z. Zhu and J. H. Espenson, J. Org. Chem., 1996, 61, 324-328.

36 M. Snåre, I. Kubičková, P. Mäki-Arvela, K. Eränen and D. Y. Murzin, Ind. Eng. Chem. Res., 2006, 45, 5708-5715. 